\title{
The Shape of the Oral Glucose Tolerance Test-Glucose Response Curve in Islet Cell Antibody-Positive vs. -Negative Obese Youth Clinically Diagnosed with Type 2 Diabetes
}

\author{
Joon Young Kim ${ }^{1, *}$, Hala Tfayli ${ }^{2}$, Fida Bacha ${ }^{3}$, Silva Arslanian ${ }^{4,5}$ \\ 'Department of Exercise Science, David B. Falk College of Sport and Human Dynamics, Syracuse University, Syracuse, New York, NY, USA; ${ }^{2}$ Department of Pediatrics \\ and Adolescent Medicine, American University of Beirut Medical Center, Beirut, Lebanon; ${ }^{3}$ Children's Nutrition Research Center, Baylor College of Medicine, Houston, \\ $T X_{i}{ }^{4}$ Center for Pediatric Research in Obesity and Metabolism, UPMC Children's Hospital of Pittsburgh, Pittsburgh, PA; ${ }^{5}$ Division of Pediatric Endocrinology, \\ Metabolism and Diabetes Mellitus, UPMC Children's Hospital of Pittsburgh, Pittsburgh, PA, USA
}

Background: The oral glucose tolerance test (OGTT)-glucose response curves (GRCs; incessant increase, monophasic, and biphasic) reflect insulin sensitivity and $\beta$-cell function, being worse in the former and superior in the latter. Here, we examined if the OGTT-GRC pattern is worse in obese antibody (glutamic acid decarboxylase 65-kDa [GAD65] and insulinoma-associated protein-2 [IA-2])-positive (Ab+) vs. -negative (Ab-) youth clinically diagnosed with type 2 diabetes (CDX-T2D).

Methods: Forty-seven obese youth, $15 \mathrm{Ab}^{+}$and $32 \mathrm{Ab}^{-}$, were divided into three OGTT-GRC groups: incessant increase, monophasic, and biphasic. The prevalence of OGTT-GRC, clamp-measured insulin sensitivity, and $\beta$-cell function was compared.

Results: Incessant increase OGTT-GRC is the most frequent curve type and is three-fold higher in $\mathrm{Ab}^{+} \mathrm{Vs} . \mathrm{Ab}^{-}$ youth CDX-T2D. In $\mathrm{Ab}^{+}$youth, there was up to $40 \%$ lower second-phase insulin secretion in the incessant increase group vs. the other two groups combined (monophasic and biphasic). In Ab- youth, while first- and second-phase insulin secretion was significantly lower in the incessant increase vs. the other two groups combined, overall $\beta$-cell function was less impaired than in $\mathrm{Ab}^{+}$youth. In neither $\mathrm{Ab}^{-}$or $\mathrm{Ab}^{+}$youth was OGTT-GRC related to hepatic or peripheral insulin sensitivity.

Conclusion: Severe insulin deficiency, a characteristic of type 1 diabetes, seems to be related to higher prevalence of incessant increase in $\mathrm{Ab}^{+} \mathrm{vs}$. Ab- obese youth.

Key words: Oral glucose tolerance test, Glucose intolerance, Insulin resistance, Insulin secretion, Type 2 diabetes mellitus, Obesity, Adolescent
Received August 25, 2020

Reviewed March 17, 2021

Accepted March 26, 2021

${ }^{*}$ Corresponding author Joon Young Kim

(iD) https://orcid.org/0000-0003-0448-1684

Department of Exercise Science, David B. Falk College of Sport and Human Dynamics, Syracuse University, Women's Building 204E, 820 Comstock Ave, Syracuse, NY 13244, USA Tel: +1-315-443-1411

Fax: +1-315-443-9375

E-mail: jkim291@syr.edu

\section{INTRODUCTION}

In non-diabetic youth, the shape of the glucose response curve (GRC) during an oral glucose tolerance test (OGTT) portends the metabolic risk for type 2 diabetes, such that individuals with a monophasic-GRC have lower in vivo insulin sensitivity and $\beta$-cell function than those with a biphasic-GRC independent of fasting and 2-hour glucose concentrations. ${ }^{1}$ While continuous increase in plasma glucose concentration during the 2-hour OGTT (i.e., incessant increase-GRC) is rare in non-diabetic obese youth, a recent TODAY (Treatment Options for Type 2 Diabetes in Adolescents and Youth) investigation of the OGTT-GRC showed a $22 \%$ preva-

Copyright @ 2021 Korean Society for the Study of Obesity

(a) This is an Open Access article distributed under the terms of the Creative Commons Attribution Non-Commercial License (https://creativecommons.org/licenses/by-nc/4.0/) which permits unrestricted non-commercial use, distribution, and reproduction in any medium, provided the original work is properly cited. 
lence of incessant increase-GRC in obese youth with type 2 diabetes. ${ }^{2}$ Furthermore, this incessant increase-GRC was indicative of severe metabolic dysregulation evidenced by lower baseline oral disposition index and higher glycemic failure rate in response to any treatment modalities compared with the other two OGTTGRC patterns (monophasic and biphasic). ${ }^{2}$ We previously demonstrated that obese youth clinically diagnosed with type 2 diabetes (CDX-T2D) who are islet cell antibody (glutamic acid decarboxylase $65-\mathrm{kDa}$ [GAD65] and insulinoma-associated protein-2 [IA$2])$-positive $\left(\mathrm{Ab}^{+}\right)$have greater impairment in $\beta$-cell function, while those who are antibody-negative $\left(\mathrm{Ab}^{-}\right)$have worse insulin sensitivity. ${ }^{3}$ As such, we postulated that the OGTT-GRC pattern would be worse in obese $\mathrm{Ab}^{+}$youth than in $\mathrm{Ab}^{-}$youth. Therefore, the purpose of the study was (1) to compare the prevalence of OGTT-GRCs (incessant increase, monophasic, and biphasic) between obese $\mathrm{Ab}^{+}$vs. $\mathrm{Ab}^{-}$youth CDX-T2D and (2) to investigate differences in clamp-measured peripheral insulin sensitivity and $\beta$-cell function (first- and second-phase insulin secretion) according to pattern of OGTT-GRC in $\mathrm{Ab}^{+}$and $\mathrm{Ab}^{-}$youth CDX-T2D.

\section{METHODS}

\section{Participants}

Data from 47 obese adolescents with a clinical diagnosis of type 2 diabetes, made by the attending endocrinologist in the Diabetes Center at UPMC Children's Hospital of Pittsburgh, PA, USA, were used in the present analysis. ${ }^{3,4}$ Clinical and laboratory characteristics of obese youth with type 2 diabetes at the time of diagnosis, including presence of symptoms, ketones, glucose concentrations, glycosylated hemoglobin ( $\mathrm{HbAlc}$ ), and treatment modalities and/ or insulin use at diagnosis were obtained from the medical records. ${ }^{3}$ Of them, islet cell antibody (GAD65 and IA-2) screening revealed 15 positive and 32 negative cases. Islet cell antibodies were tested using the National Institute of Diabetes and Digestive and Kidney Diseases-sponsored harmonization assay. ${ }^{3,4}$ Additional inclusion criteria of the study were (1) age 10-18 years, (2) Tanner stage II$\mathrm{V}$, (3) body mass index (BMI) $\geq 85$ th percentile for age and sex, and (4) duration of diabetes $\leq 7$ years. Exclusion criteria were (1) presence of another disease or chronic medication that could interfere with endocrine function, (2) HbAlc > 8.5\%, (3) HemoCue
$<12 \mathrm{~g} / \mathrm{dL}$, and (4) positive pregnancy test (serum). The Institutional Review Board of the University of Pittsburgh approved this study (IRB No. IRB0405513), and written informed parental consent and child assent were obtained prior to the investigation.

\section{Procedures}

All participants admitted to the Pediatric Clinical and Translational Research Center of Children's Hospital of Pittsburgh underwent medical history, physical examination, and hematologic and biochemical tests. Tanner criteria ${ }^{5}$ were used for assessing pubertal development. Dual-energy X-ray absorptiometry was used for body composition measures.

\section{Metabolic studies}

The Supplementary Material 1 describes details of metabolic studies and biochemical measurements (glucose, insulin, and enrichments of glucose). All participants received a 3-hour hyperinsulinemic-euglycemic clamp together with stable isotope tracer and a 2-hour hyperglycemic clamp after 10-12 hours of fasting within a 1- to 4-week period in random order. ${ }^{3,6}$ Fasting hepatic glucose production (HGP) was measured by $\left[6,6-{ }^{2} \mathrm{H}_{2}\right]$ glucose as described previously. ${ }^{7}$ Peripheral insulin sensitivity was measured during hyperinsulinemic $\left(80 \mathrm{mU} / \mathrm{m}^{2} / \mathrm{min}\right)$-euglycemic clamp. ${ }^{3,6}$ First- and second-phase insulin secretion were assessed during hyperglycemic (225 mg/dL) clamp. ${ }^{3,6}$

\section{Calculations}

Fasting HGP was calculated during the last 30 minutes of the 2-hour isotope infusion. ${ }^{7}$ Hepatic insulin sensitivity was calculated as $1 /$ (fasting $\mathrm{HGP} \times$ fasting insulin $).{ }^{8}$ Insulin-stimulated glucose disposal $(\mathrm{Rd})$ was calculated as the rate of exogenous glucose infusion during the final 30 minutes of hyperinsulinemic-euglycemic clamp. ${ }^{7,8}$ Peripheral insulin sensitivity was calculated as $(\mathrm{Rd} /$ steadystate clamp insulin) $\times 100$. During hyperglycemic clamp, first- and second-phase insulin secretion were calculated during the first 10 minutes and between 15 to 120 minutes, respectively. ${ }^{7}$

\section{Classification of OGTT-GRCs and statistical analysis}

Participants who completed a 2-hour OGTT $(1.75 \mathrm{~g} / \mathrm{kg}$, maximum $75 \mathrm{~g}$ ) were divided into three OGTT-GRC groups: incessant 
increase, monophasic, and biphasic. ${ }^{1,2}$ For visualization of OGTTGRCs, selective individual curves for each category are shown in the Supplementary Material 1. An incessant increase-GRC was defined as a gradual continuous increase without subsequent decrease in glucose $\geq 4.5 \mathrm{mg} / \mathrm{dL}$. A monophasic-GRC was determined by a gradual increase in glucose concentration to a peak (between 30 to 90 minutes during the test), followed by a decrease $\geq 4.5 \mathrm{mg} / \mathrm{dL}$. A biphasic-GRC was defined by a second increase in glucose concentration of $\geq 4.5 \mathrm{mg} / \mathrm{dL}$ after a decrease $\geq 4.5 \mathrm{mg} / \mathrm{dL}$. The prevalence of OGTT-GRC between $\mathrm{Ab}^{+}$vs. $\mathrm{Ab}^{-}$youth was compared by chi-square test. Because of the low prevalence of the biphasic curve and the overall small sample size, independent sample t-tests were used to compare physical and metabolic characteristics of individuals with the incessant increase-GRC vs. those with the two other GRCs combined (monophasic and biphasic) in $\mathrm{Ab}^{+}$and $\mathrm{Ab}^{-}$ youth. Analysis of covariance was used to adjust for treatment mo-

Table 1. Participants' demographic, physical, and metabolic characteristics

\begin{tabular}{|c|c|c|c|}
\hline \multirow{2}{*}{ Variable } & \multicolumn{2}{|c|}{ Clinically diagnosed type 2 diabetes } & \multirow{2}{*}{$P$} \\
\hline & $A b^{-}(n=32)$ & $A b^{+}(n=15)$ & \\
\hline Age (yr) & $15.03 \pm 0.3$ & $14.33 \pm 0.62$ & NS \\
\hline Sex (male:female) & 16:16 & 5:10 & NS \\
\hline Ethnicity (AA:AW) & 17:15 & $5: 10$ & NS \\
\hline Tanner stage (II:III:IV:V) & 2:1:9:20 & 2:1:2:10 & NS \\
\hline $\mathrm{BMI}\left(\mathrm{kg} / \mathrm{m}^{2}\right)$ & $36.7 \pm 0.9$ & $30.5 \pm 1.3$ & $<0.001$ \\
\hline $\mathrm{HbA1c}(\%)$ & $6.6 \pm 0.1$ & $6.4 \pm 0.3$ & NS \\
\hline Fat mass (kg) & $41.3 \pm 1.9$ & $32.9 \pm 2.9$ & 0.016 \\
\hline Percent body fat & $42.3 \pm 1.2$ & $40.0 \pm 2.1$ & NS \\
\hline Diabetes duration (mo) & $7.5 \pm 1.7$ & $5.7 \pm 1.1$ & NS \\
\hline Treatment modality & & & NS \\
\hline Lifestyle & $6(19)$ & $2(13)$ & \\
\hline Insulin & $4(12)$ & $3(20)$ & \\
\hline Metformin & $15(47)$ & $2(13)$ & \\
\hline Metformin and insulin & $7(22)$ & $8(54)$ & \\
\hline Fasting glucose (mg/dL) & $113.9 \pm 4.6$ & $129.3 \pm 10.9$ & NS \\
\hline OGTT 2-hour glucose (mg/dL) & $197.9 \pm 9.7$ & $299.1 \pm 21.0$ & $<0.001$ \\
\hline Fasting C-peptide (ng/mL) & $4.2 \pm 0.3$ & $2.2 \pm 0.3$ & $<0.001$ \\
\hline OGTT 2-hour C-peptide (ng/mL) & $10.7 \pm 0.6$ & $4.8 \pm 0.6$ & $<0.001$ \\
\hline \multicolumn{4}{|l|}{ Hyperglycemic clamp parameter } \\
\hline 1st-phase insulin ( $\mu \mathrm{U} / \mathrm{mL})$ & $123.5 \pm 26.6$ & $34.5 \pm 4.6$ & 0.002 \\
\hline 2nd-phase insulin ( $\mu \mathrm{U} / \mathrm{mL})$ & $168.8 \pm 23.9$ & $45.8 \pm 7.4$ & $<0.001$ \\
\hline \multicolumn{4}{|c|}{ Hyperinsulinemic-euglycemic clamp parameter } \\
\hline Peripheral IS (mg/kg/min per $\mu \mathrm{U} / \mathrm{mL}$ ) & $1.5 \pm 0.2$ & $3.3 \pm 0.5$ & $<0.001$ \\
\hline
\end{tabular}

Values are presented as mean \pm standard error of the mean or number $(\%)$. NS, not significant; AA, African American; AW, American White; BMl, body mass index; HbA1c, glycosylated hemoglobin; OGT, oral glucose tolerance test; IS, insulin sensitivity. dalities, diabetes duration, and 2-hour glucose concentration with our limited sample size. Non-normally distributed data were $\log _{10}$ transformed: untransformed data are presented for ease of interpretation. The IBM SPSS ver. 24.0 (IBM Corp., Armonk, NY, USA) was used, and data are presented as mean \pm standard error of the mean unless otherwise specified.

\section{RESULTS}

In the present study, comparisons of insulin sensitivity and $\beta$-cell function between obese $\mathrm{Ab}^{+}(\mathrm{n}=15)$ vs. $\mathrm{Ab}^{-}(\mathrm{n}=32)$ youth CDXT2D were concordant with our previous publications: ${ }^{3,4} \mathrm{Ab}^{+}$youth had greater impairments in first- and second-phase insulin secretion compared with $\mathrm{Ab}^{-}$youth, while the latter group showed severe hepatic and peripheral insulin resistance in the absence of differences in age, sex, ethnicity, Tanner stage, percent body fat, diabetes duration, and treatment modalities (Table 1).

An incessant increase-GRC was dominant in $\mathrm{Ab}^{+}$youth (73\%), but present only in $25 \%$ of $\mathrm{Ab}^{-}$youth $(P=0.006)$. In contrast, the prevalence of a monophasic-GRC was higher in $\mathrm{Ab}^{-} \mathrm{vs}$. $\mathrm{Ab}^{+}$youth (66\% vs. $20 \%, P=0.006$ ). A biphasic-GRC was present in only one $\mathrm{Ab}^{+}(7 \%)$ and three $\mathrm{Ab}^{-}$(9\%) youth (Fig. 1).

From our analysis of $\mathrm{Ab}^{+}$youth only, hyperglycemic clamp-measured second-phase insulin secretion was $\sim 40 \%$ lower in the incessant increase-GRC vs. the other two groups combined (monopha-

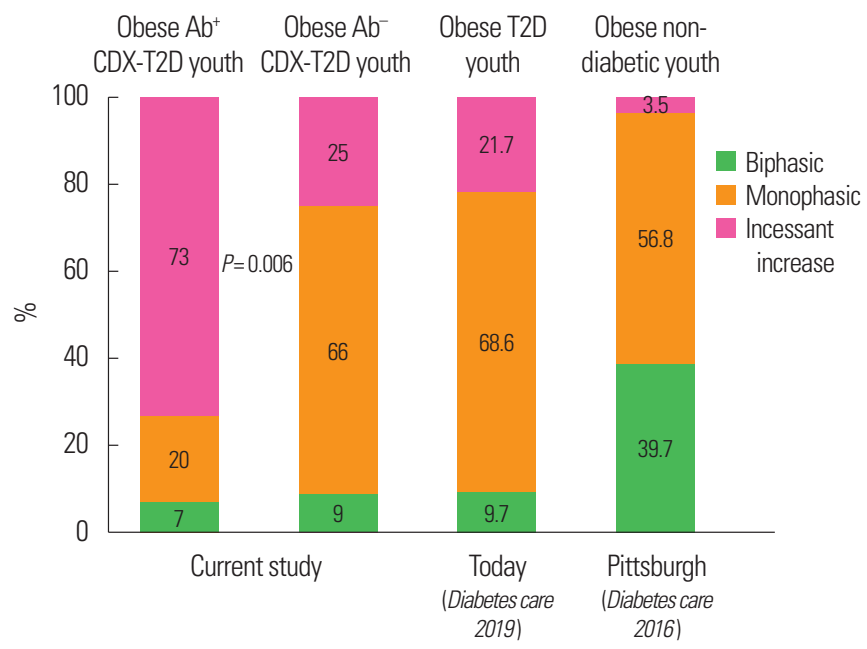

Figure 1. Prevalence of the glucose response curve during an oral glucose tolerance test in diabetic and non-diabetic youth. ${ }^{1,2}$ CDX-T2D, clinically diagnosed with type 2 diabetes. 

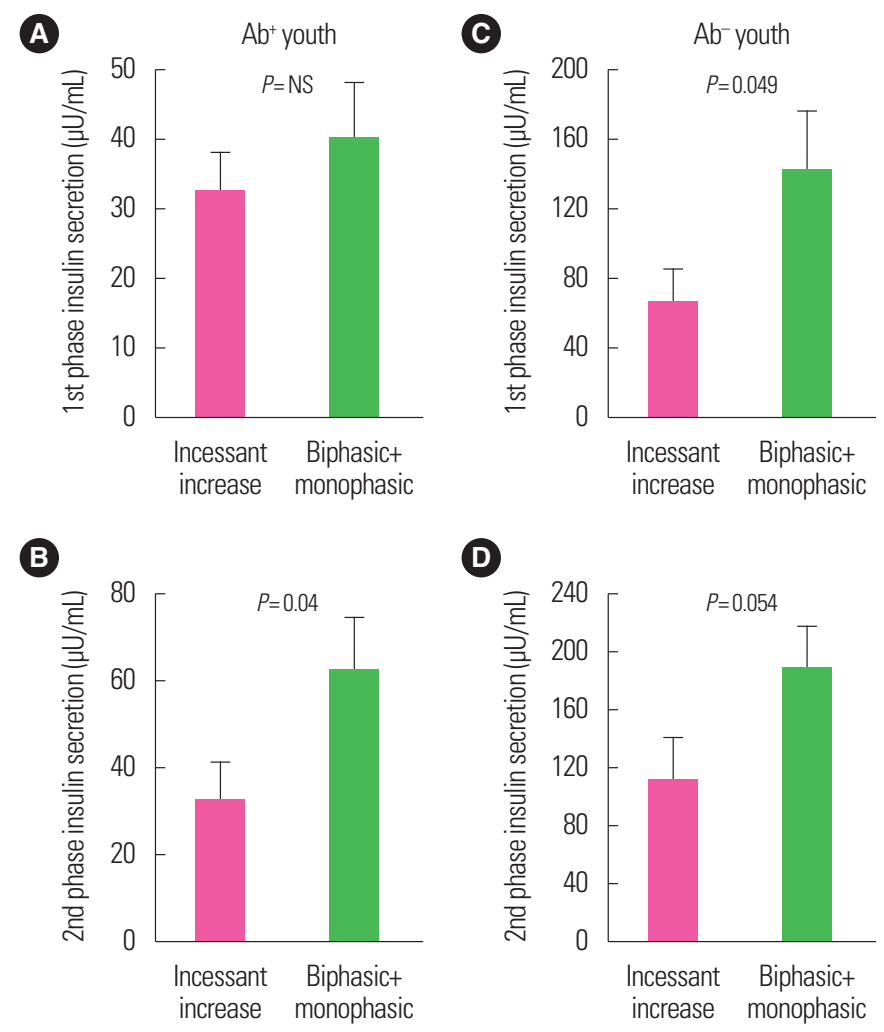

Figure 2. Hyperglycemic clamp-measured insulin secretion in obese $A b^{+}(A, B)$ and $\mathrm{Ab}^{-}(\mathrm{C}, \mathrm{D})$ youth clinically diagnosed with type 2 diabetes by the glucose response curve during an oral glucose tolerance test type. Values are presented as mean \pm standard error of the mean. NS, not significant.

sic and biphasic) (Fig. 2A, B). There was up to $20 \%$ lower firstphase insulin secretion in the incessant increase-GRC vs. the other two groups, which was not a significant difference. There were no differences in age, sex, race, Tanner stage, BMI, percent body fat, and hepatic and peripheral insulin sensitivity between the $\mathrm{Ab}^{+}$ group with incessant increase-GRC and the groups with monophasic- or biphasic-GRC. For the $\mathrm{Ab}^{-}$group, youth with an incessant increase-GRC had lower first- and second-phase insulin secretion (53\% and $42 \%$, respectively) compared with those with monophasic- or biphasic-GRC (Fig. 2C, D) in the absence of differences in age, sex, race, Tanner stage, BMI, percent body fat, hepatic, and peripheral insulin sensitivity. Our significant findings of insulin secretion according to pattern of OGTT-GRC in the $\mathrm{Ab}^{+}$ and $\mathrm{Ab}^{-}$groups remained significant after adjustment for treatment modalities, whereas no statistical significance existed after adjusting for diabetes duration and/or OGTT 2-hour glucose concentration.

\section{DISCUSSION}

The present investigation demonstrates that an incessant increase OGTT-GRC, considered a more severe curve phenotype than the other GRCs, is common in obese youth CDX-T2D, both $\mathrm{Ab}^{+}$and $\mathrm{Ab}^{-}$, in contrast to non-diabetic youth. ${ }^{1}$ Furthermore, the prevalence of incessant increase-GRC is 3-fold higher in $\mathrm{Ab}^{+}$vs. $\mathrm{Ab}^{-}$obese youth CDX-T2D. In both $\mathrm{Ab}^{+}$and $\mathrm{Ab}^{-}$youth, an incessant increase-GRC reflects severe impairment in $\beta$-cell function compared with the other two combined, monophasic- and biphasic-GRCs.

The OGTT-GRC has been recognized as a useful indicator of insulin resistance and $\beta$-cell dysfunction in non-diabetic youth; ${ }^{1,9-11}$ however, only one study (i.e., TODAY clinical trial) has examined its utility in youth with type 2 diabetes. ${ }^{2}$ The prevalence of the different OGTT-GRCs in obese $\mathrm{Ab}^{-}$youth CDX-T2D in the current study is consistent with the TODAY data: $25 \%$ of $\mathrm{Ab}^{-}$youth had incessant increase-GRC in this study and $22 \%$ in the TODAY (Fig. 1). In both studies, insulin sensitivity (measured by hyperinsulinemic-euglycemic clamp in ours and by OGTT in TODAY) did not differ among OGTT-GRCs, whereas insulin secretion was impaired in the incessant increase-GRC compared with monophasic- and biphasic-GRCs, suggesting that the OGTT-GRCs can differentiate $\beta$-cell function but not insulin sensitivity in type 2 diabetes. This observation was in contrast to the non-diabetic cases where OGTT-GRC was reflective of both insulin sensitivity and $\beta$-cell function. ${ }^{1}$

There are limited data with respect to the OGTT-GRC in youth with type 1 diabetes. The TrialNet study recently showed that the majority of $\mathrm{Ab}^{+}$relatives of individuals with type 1 diabetes had a monophasic- (66\%) vs. biphasic-GRC (34\%), with a higher cumulative incidence of type 1 diabetes during the follow-up period. ${ }^{12}$ Since the aforementioned study did not include the incessant increase-GRC type in $\mathrm{Ab}^{+}$individuals with relatives of type 1 diabetes, and due to the fact that our $\mathrm{Ab}^{+}$youth were obese with clinically diagnosed type 2 diabetes, we were not able to confirm or negate the findings between these two studies. In the present study of obese $\mathrm{Ab}^{+}$youth CDX-T2D, the incessant increase-GRC reflected severe impairment in $\beta$-cell function (second-phase insulin secretion) compared with monophasic- and biphasic-GRCs combined. 
Given the greater impairment in $\beta$-cell function in $\mathrm{Ab}^{+} \mathrm{vs}$. $\mathrm{Ab}^{-}$obese youth CDX-T2D in the present data and our previous publication, ${ }^{3}$ we postulate that the higher prevalence of the incessant increaseGRC in $\mathrm{Ab}^{+}$compared with $\mathrm{Ab}^{-}$obese youth is due to severe insulin deficiency, which is a major characteristic of type 1 diabetes.

Our limited number of participants in the present study hinders our ability to (1) specify potential impacts of differences in diabetes duration and degree of hyperglycemia on OGTT-GRCs together with $\beta$-cell impairment and (2) generalize the characteristics of the OGTT-GRCs in an overall population of $\mathrm{Ab}^{+}$and $\mathrm{Ab}^{-}$obese youth CDX-T2D. Studies in larger cohorts of youth with diabetes are needed to confirm distinguishing features of the various OGTT-GRCs between $\mathrm{Ab}^{+}$vs. $\mathrm{Ab}^{-}$youth. Moreover, we acknowledge the possibility of latent autoimmune diabetes in future adults of obese $\mathrm{Ab}^{+}$youth, yet there are no clear clinical methods to eliminate such participants. Lastly, while the three treatment modalities in the TODAY study did not modulate OGTT-GRC over time, ${ }^{2}$ it remains unknown if weight reduction or insulin sensitizers enhance OGTT-GRC in $\mathrm{Ab}^{+}$youth.

In summary, our data suggest that OGTT-GRCs can differentiate unique characteristics of $\mathrm{Ab}^{+} \mathrm{vs}$. $\mathrm{Ab}^{-}$obese youth with clinically diagnosed type 2 diabetes. Higher prevalence of incessant increaseGRC in obese youth with $\mathrm{Ab}^{+}$vs. $\mathrm{Ab}^{-}$is synchronized with the severe $\beta$-cell dysfunction observed in $\mathrm{Ab}^{+}$youth.

\section{CONFLICTS OF INTEREST}

Joon Young Kim is the Editorial Board member of the Journal of Obesity \& Metabolic Syndrome. However, he is not involved in the peer reviewer selection, evaluation, or decision process of this article. Otherwise, no other potential conflicts of interest relevant to this article were reported.

\section{ACKNOWLEDGMENTS}

The authors thank the children who took part in the research that comprises our data and their parents for their support.

This study was supported by K24-HD01357 to S.A. and by UL1TR-000005 Clinical and Translational Science Award (CTSA) and RR024153 to GCRC.

\section{AUTHOR CONTRIBUTIONS}

Study concept and design: JYK and SA; acquisition of data: HT, FB, and SA; analysis and interpretation of data: JYK and SA; drafting of the manuscript: JYK; critical revision of the manuscript: all authors; statistical analysis: JYK and SA; obtained funding: SA; administrative, technical, or material support: JYK and SA; and study supervision: JYK and SA.

\section{SUPPLEMENTARY MATERIALS}

Supplementary Material 1 can be found via https://doi.org/10. 7570/jomes20088.

\section{REFERENCES}

1. Kim JY, Michaliszyn SF, Nasr A, Lee S, Tfayli H, Hannon T, et al. The shape of the glucose response curve during an oral glucose tolerance test heralds biomarkers of type 2 diabetes risk in obese youth. Diabetes Care 2016;39:1431-9.

2. Arslanian S, El Ghormli L, Young Kim J, Bacha F, Chan C, Ismail HM, et al. The shape of the glucose response curve during an oral glucose tolerance test: forerunner of heightened glycemic failure rates and accelerated decline in $\beta$-cell function in TODAY. Diabetes Care 2019;42:164-72.

3. Tfayli H, Bacha F, Gungor N, Arslanian S. Phenotypic type 2 diabetes in obese youth: insulin sensitivity and secretion in islet cell antibody-negative versus -positive patients. Diabetes 2009;58:738-44.

4. Tfayli H, Bacha F, Gungor N, Arslanian S. Islet cell antibodypositive versus -negative phenotypic type 2 diabetes in youth: does the oral glucose tolerance test distinguish between the two? Diabetes Care 2010;33:632-8.

5. Tanner JM. Growth and maturation during adolescence. Nutr Rev 1981;39:43-55.

6. Bacha F, Gungor N, Lee S, Arslanian SA. In vivo insulin sensitivity and secretion in obese youth: what are the differences between normal glucose tolerance, impaired glucose tolerance, and type 2 diabetes? Diabetes Care 2009;32:100-5.

7. Arslanian SA, Lewy VD, Danadian K. Glucose intolerance in 
obese adolescents with polycystic ovary syndrome: roles of insulin resistance and beta-cell dysfunction and risk of cardiovascular disease. J Clin Endocrinol Metab 2001;86:66-71.

8. Arslanian S, Kim JY, Nasr A, Bacha F, Tfayli H, Lee S, et al. Insulin sensitivity across the lifespan from obese adolescents to obese adults with impaired glucose tolerance: who is worse off? Pediatr Diabetes 2018;19:205-11.

9. Kim JY, Coletta DK, Mandarino LJ, Shaibi GQ. Glucose response curve and type 2 diabetes risk in Latino adolescents. Diabetes Care 2012;35:1925-30.

10. Nolfe G, Spreghini MR, Sforza RW, Morino G, Manco M.
Beyond the morphology of the glucose curve following an oral glucose tolerance test in obese youth. Eur J Endocrinol 2012;166:107-14.

11. Bervoets L, Mewis A, Massa G. The shape of the plasma glucose curve during an oral glucose tolerance test as an indicator of Beta cell function and insulin sensitivity in end-pubertal obese girls. Horm Metab Res 2015;47:445-51.

12. Ismail HM, Xu P, Libman IM, Becker DJ, Marks JB, Skyler JS, et al. The shape of the glucose concentration curve during an oral glucose tolerance test predicts risk for type 1 diabetes. Diabetologia 2018;61:84-92. 